\title{
An empirical study of the European corporate leniency program
}

\author{
Steffen Brenner* \\ Humboldt-University Berlin
}

March 15, 2005

${ }^{*}$ Humboldt-University Berlin, Department of Economics, Institute of Management, Spandauer Strasse 1, D-10178 Berlin, Phone.:+49.30.2093-5639, brenner@gmx.li 


\begin{abstract}
Leniency programs are widely used as instruments of competition policy. They are supposed to serve two purposes: in the short-run to facilitate the detection of cartels and thereby to reduce cost of legal enforcement, and in the long-run to deter firms from antitrust abuse. In our empirical study of the 1996 EU Leniency Program, we find strong evidence that the program provides incentives to reveal information on criminal activities in the sense that agencies are better informed about the cartel conduct than they would be absent the program. Despite of that, investigation and prosecution cost reductions seem to be rather modest.

On deterrence, we neither find that the leniency program stabilizes cartels through facilitating punishing strategies, nor do we find that cartels are destabilized because defecting from a cartel becomes less costly. The sharp rise in the number of convicted cartels after introducing the program may be attributed to a rise of cartel activity caused by an accelerated market integration in the EU in the beginning of the 1990s.
\end{abstract}

Journal of Economic Literature Classification: K21, K41, L4

Key words: cartel stability, leniency, amnesty, self-reporting, antitrust 


\section{Introduction}

Entitling criminals to reduced fines in exchange for a confession of the harmful act has become wide-spread across different legal systems. The principal motivation for policy-makers to adopt a policy of leniency in such cases is the reduction of investigation cost through achieving cooperation with the criminal (Kaplow and Shavell 1994). What seems not so clear is the long-term impact of a leniency program on criminal behavior. Does it actually deter or encourage potential wrong-doers? In particular in dynamic situations with a group of criminals involved, it may not be easy to predict whether such a program would have a destabilizing effect on the criminal organization. Although leniency programs have potentially a serious effect on how efficient the legal system works, empirical studies on the efficiency of this policy instrument do not yet exist.

In this paper, we examine the efficiency of the EU Leniency Program in the area of antitrust enforcement. Conducting an empirical study in this area (compared to "non-corporate" areas) may prove useful because collusive behavior as one of the crimes committed by "firms" received much attention by economic theorists which in turn facilitates the empirical analysis 11 Furthermore, in many jurisdictions leniency programs have only recently been adopted, making it easier to compare the success of antitrust enforcement contingent on whether a leniency program was in force or

\footnotetext{
${ }^{1}$ In this paper, we take the view that the manager's interest is totally aligned with the firm's (or finally its shareholders') interest. This would be less plausible if managers could be held personally responsible for the committed crime.
} 
not. 2

In order to assess the efficiency of a leniency program, a variety of effects such a program potentially implicates on social welfare have to be considered. On the one-hand side, there are short-term benefits occurring after the cartel has formed. Leniency programs basically create a prisoners dilemma situation, in which the confessing party gets rewarded (by reduced fines or even by positive payments). If successful, the leniency program is welfare enhancing through accomplishing a cessation of the collusive behavior. Further, cooperation by cartel members in the period in which the antitrust agency collects evidence may be socially desirable because investigation by the authority requires scarce resources (Kaplow and Shavell 1994, Motta and Polo 2003). Hence, it helps to save investigation cost. More on this point, it is a procedure which only with a certain probability leads to a full documentation of the cartel activities. Thus, self-reporting provides further benefits to the society if it finally provides richer evidence on which a conviction can be based on. However, a potential disadvantage of frequent self-reporting is that the agencies may become overloaded with the task of assessing penalties perhaps outweighing the benefits in the investigation phase (Kaplow and Shavell 1994, Innes 1999).

On the other hand, taking a long-term perspective, there is the question whether a leniency program has an impact on the firms' decisions at the date of cartel forma-

\footnotetext{
${ }^{2}$ In the US, the first amnesty program was installed in 1978. It was revised in 1993 giving more incentives to report spontaneously. In the EU, this policy instrument was introduced in 1996, and it was similarly modified in 2002 .
} 
tion. Spagnolo (2003) identified the following three reasons why cartels may be less stable facing a leniency program. First, it just changes the cost/benefit ratio of collusion since deviating and reporting yields lower costs/higher benefits than absent a leniency program. Secondly, considering stick-and-carrot punishment strategies (Abreu 1988), punishment of second-time deviators is less efficient with the possibility of immunity. Thirdly, the perceived risk of a collusive agreement à la Harsanyi and Selten (1988) is higher to firms facing a leniency program. Additionally, there is another conceivable effect that may occur if leniency programs imply a strong effect of information revelation. The documentation of the cartel activities may be more complete than without a leniency program. This may lead to a situation in which total fines associated with a case are higher even after reduction for leniency, making collusion ex ante less attractive.

However, a potential downside of such a program exists since other effects perhaps dilute deterrence. To begin with, the expected amount of fines is reduced which makes it ex ante less costly to enter a cartel if the level of fines is not adjusted. Further, collusive agreements are oftentimes not stable unless a mechanism exists which can be used to punish a cheating party. If a leniency program is restricted to the first reporting firms, it is an ideal instrument for punishing a (non-reporting) deviator (Spagnolo 2003, Ellis and Wilson 2001).

In summary, we expect that after introducing a leniency program, collecting evidence is a less costly activity for the authority and cases are more completely and more solidly documented. Predictions concerning the long-run effects of deterrence 
are less exact.

Studying cartels empirically presents a series of pitfalls of which the most important is that not the whole population of cartels can be observed. Indeed, cartel studies conducted before were either constrained to the domain of legal activities or otherwise had to deal with the problem that any analysis based on prosecuted cartels is subject to serious sample bias ${ }^{3}$

To address our research question, we can circumvent the illustrated problem. Concerning the short-run efficiency, we anyway concentrate on cartels conditional on being detected. Concerning the long-run effect of deterrence, we make our strongest inferences using a sub-sample consisting of cartel cases of which all were established before the leniency policy was adopted. Then estimating a hazard model discloses whether those cartels being created under similar conditions break down more easily in the presence of a leniency program.

The first version of the European Union Leniency Program (European Commission 1996) came into force in 1996 . The program promises a $75-100 \%$ reduction of fines to the first company which fully cooperates before an investigation has been initiated and a $50-75 \%$ reduction for the first firm which fully cooperates after an investigation has started. Further confessing firms are eligible to reductions of 10 $50 \%$. Thus this scheme provides incentives to deliver evidence even at later stages of

\footnotetext{
${ }^{3}$ For example, regarding the question whether cartelization is more likely in some industries, Posner (1970) stated that it is not obvious whether industries for which a higher number of cartels are observed are collusion-prone or investigation-prone.
} 
the investigation. It is important to note that on the level of the European Union, there are no legal sanctions for anticompetitive behavior regarding the individuals involved. The program can be classified as a "moderate" leniency scheme. $4^{4}$

The sample consists of 245 firms which were involved in 53 cartel cases investigated and prosecuted by the European Commission between 1990 and 2003. Empirically, we find that the program induces a high level of information revelation, while its design seems to be too moderate in order to imply a deterrence effect. In particular, we find that, controlling for a variety of factors influencing the level of fines, cartels under the leniency program are imposed higher fines than their counterparts (before reduction based on leniency). Moreover, cartels exhibiting a higher degree of cooperation between cartelists and the antitrust agency are on average fined more heavily in total (again, before reduction based on leniency). To the extent that the level of fines is influenced by how well the case is documented (controlling for other factors), this confirms our expectation that additional information is revealed to the agency which it would not have access to without self-reporting. The impact of the leniency program on investigation and prosecution cost, however, is weak.

Regarding the deterrence effect, despite the fact that the European Commission witnessed a strong rise in the number of convictions after 1996, we do not find evidence that cartels become more fragile after adopting the leniency instrument. Even considering the hazard of those cartels in which spontaneous self-reporting

\footnotetext{
4"Moderate" leniency programs may be defined as programs in which no rewards are distributed and in which more than the first reporting party may receive leniency reductions.
} 
(or self-denouncing) occurred we cannot identify significant difference in stability to other cartels when we take interaction into account with related cases under the US jurisdiction. The rise in the number of convicted cartels can be plausibly linked to a coinciding increase of cartel activity in the beginning of the 1990s and the following years caused by political measures of market integration on the level of the European Union.

To the best of our knowledge, this is the first study to empirically investigate a program which provides immunity from fines for wrong-doers 5 . However, a related paper by Apesteguia, Dufwenberg and Selten (2004) examines the topic experimentally. The authors use a Bertrand game with or without communication between players as the standard setting and compare it to a "leniency" and a "bonus" treatment. The leniency scheme offers a fixed percentage reduction of fines which is shared between all the reporting firms. It differs from the EU program in the sense that it does not distinguish between the temporal order applications for leniency arrive. The bonus scheme can be interpreted as a high-powered leniency program. It entitles firms reporting to the agency a reward equal to the fines payed by nonreporting firms. Apesteguia, Dufwenberg and Selten (2004) find that the leniency scheme indeed provides a deterrent effect as it implies the lowest number of cartels formed. In this way, it contrasts with our empirical results. Nevertheless, given that in the experiment there were no repeated interactions between individuals, it

\footnotetext{
${ }^{5}$ The deterrence effect of fines and capital punishment (ignoring any immunity caused by selfreporting) was, for example, investigated by Bar-Ilan and Sacerdote (2004) and Mocan and Gittings (2003).
} 
is not surprising that collusion is less likely to be sustainable. However, unexpectedly, under the bonus scheme individuals show the highest propensity to collude. The authors conjecture that they chose the strategy of colluding and reporting in order to take the chance of collecting high cartel profits and a reward for reporting (expecting others not to report). However, reporting activity was very high under this scheme, such that this loss-making strategy may not be sustained if the games were played more frequently. Anyway, none of the existing leniency programs in the area of antitrust legislation does entitle reporting cartelists to rewards.

The organization of the paper is as follows. In the next section we give a short review of the related literature and we develop hypotheses. The data set is described in Section 3 before we present the empirical results. Finally, the paper is concluded.

\section{Previous literature and hypotheses}

\subsection{Literature review}

It is useful to differentiate leniency programs into schemes in which firms are qualified for leniency discounts only in the post-investigation stage and into schemes in which leniency is given in the pre-investigation stage. The EU Leniency Program from 1996, the current 2002 program and the revised US Amnesty Program from 1993 are mixed forms since they are open to firms which provide evidence before and after an investigation has been initiated. 
Motta and Polo's (2003) article encompasses the study of both categories of amnesty models. They are agnostic that deterrence can be achieved by such leniency schemes. Using a dynamic model, Motta and Polo show that a program which restricts itself to spontaneous reporting before an investigation is started cannot curb the incentives to enter a cartel. In their model, a cartel which is stable absent leniency schemes must be stable as well under a pre-investigation leniency scheme since firms neither have an incentive to report before nor after an investigation is opened. Further, post-investigation leniency programs may even provide incentives to collude because the expected fines are reduced (however, because of budget constraints of the agency such a program may be optimal). Although they show that the program of post-investigation amnesty is socially only second-best, it may be optimal if resources by the agency are limited. In some situations, revelation equilibria can be established if model parameters are set accordingly. The main reason for self-reporting occurring as an equilibrium is the change in the probability of a conviction after an industry is screened. Leniency programs then promise reduced fines below expected fines without reporting to those who report. The model is close to Kaplow and Shavell's (1994) model who provide a rationale to entitle individuals for leniency in response to self-reporting in case of crimes committed individually. This mechanism helps to save enforcement resources and it provides risk-avers wrongdoers with a risk-less alternative to a probabilistic conviction.

Another contribution focussing on pre-investigation amnesty aims to study to which extent leniency programs help to deter cartels. Ellis and Wilson (2001) present 
a dynamic model of infinitely repeated Bertrand games with differentiated products. They assume that the reporting firm obtains full leniency but no reward. Given that after deviating from the cartel the trigger strategy of returning to the Nash equilibrium is employed, there are indeed incentives to report to the antitrust authority. A reporting firm raises (for one period) the marginal cost of the other cartel members by imposing a fine and by imposing further costs associated with the alignment of the company's organization with antitrust compliance. Thus, a leniency program may actually deter cartels. However, in another variant of Ellis and Wilson's model leniency, a deterrence effect cannot be established. Using a trigger strategy of selfreporting and afterwards returning to the Nash equilibrium can be used by cartel members as a punishing device as response to observing a deviation from the cartel equilibrium.

Ellis and Wilson show that the possibility of self-reporting may only have the effect of destroying the cartel equilibria of forward looking cartels, with reporting not observed. Self-reporting can also be used as disciplining instrument enforcing the cartel. However, self-reporting is not predicted by the model mainly because Ellis and Wilson model pre-investigation amnesty.

Spagnolo (2003) also uses a dynamic model with multiple cartelists to study the optimal leniency program and potential deterrence effects of non-optimal programs. In contrast to the model by Motta and Polo (2003), Spagnolo assumes that if an industry is screened, a possible cartel will be detected for sure. By considering generic punishment strategies, the first-best of deterring cartels at no cost 
can be achieved by granting leniency only to the first company and to reward this firm sufficiently. However, he establishes that even "moderate" programs (such as the one studied in our paper) can help to deter cartels. First, cartels are harder to sustain with leniency programs since defecting and reporting is more profitable. Secondly, considering stick-and-carrot punishment strategies (Abreu 1988), punishment of second-time deviators is less efficient with the possibility of immunity. Thirdly, the perceived risk in the sense of Harsanyi and Selten (1988) of a collusive agreement is higher to firms facing a leniency program.

Finally, Aubert, Kovacic and Rey (2004) pay attention to the question of who should benefit from payments by the agency. They develop mechanisms of extending the incentives to report to individuals, making leniency programs more powerful and thus colluding less profitable. The authors also discuss possible adverse effects on incentives for intra- and inter-firm cooperation. With rewards, it is shown that incentives increase to store incriminating evidence.

\subsection{Information revelation and investigation cost reduction}

One important criterion deciding about the (short-term) efficiency of a leniency program is the question of whether it provides firms with incentives to self-report to the antitrust agency. Social welfare may increase through induced self-reporting. First, if self-reporting is accompanied by a break-up of the cartel, the dead-weight loss of further collusion disappears. Further, the agency may obtain information which 
it would not have access to by relying on conventional measures of investigation $\sqrt{6}$ Moreover, even if the agency could have obtained this information, investigation may be costly, and when budgets are constrained, more cases can be handled at a time when per case costs decrease. Social costs of such a policy may be associated through a diminished deterrence effect (see next section).

Why should firms self-report? Several explanations come to the surface from the preceding literature review. First note that cartels under perfect foresight may not exhibit self-reporting behavior since those cartels in which self-reporting is profitable may not be created in the first place. However, at least two situations may induce self-reporting in reality. First, when the probability of detection exogenously increases, this option may become more valuable to cartel members vis-à-vis the option to continuing collusion (e.g., Motta and Polo 2003). Second, a cartel which is stable absent (and without expecting) a leniency program may become unstable after a leniency program is introduced. Reporting to the agency is perhaps more profitable than just stopping to collude, or to "cheat" and not to report. It reduces the expected fines in case of a conviction, it increases rivals' (marginal) costs through revenue based fines and compliance measures (Ellis and Wilson 2001), and it reduces perceived risk in the sense of Harsanyi and Selten (Spagnolo 2003).

The next related question is, why do firms keep incriminating evidence about cartel conspiracies which they could hand-in to the agency? It is not fully under-

\footnotetext{
${ }^{6}$ This raises the fines not falling under leniency for non-reporting (or late-reporting) firms and thus may even increase the deterrence effect of a leniency program.
} 
standable that firms do so in the absence of a leniency program, except for reasons of organizing and controlling the cartel (Aubert, Kovacic and Rey 2003). Any existing evidence may finally fall into the lap of the antitrust agency (e.g., after a dawn-raid) which can only worsen the legal position of a firm facing an antitrust charge since it may help to substantiate the claims brought forward by the agency. Without substantive evidence, the agency may not present a convincing case before the court. However, it is perfectly rational to store hard evidence in the context of an existing program. Thus, the existence of clear and hard evidence may be the implication of the leniency program itself.

Firms then have to decide to what extent information is revealed to the agency. If self-reporting occurs, we expect that the amount of information available to the agency will increase after the leniency program is established. It is helpful to differentiate between information easily obtainable by the agency, and information only obtainable by incurring high cost. Let us assume that "high cost" information would not be recovered by the agency without the leniency program because of a budget constraint or because the costs exceed the social benefits from obtaining the information. It is always preferred by firms to hand-in the information easily obtainable if this reduces, at least partially, their amount of fines. The other part will be revealed only if this does not increase the own fines after application of the leniency scheme. On grounds of fairness, agencies usually make sure that this effect does not occur. Since information affecting the co-conspirators' fines are externalities not taken into account by a firm's decision of how much to reveal, the total amount of 
evidence about the cartel we expect to be smaller absent the leniency program.

To sum up, even with "moderate" leniency programs as studied here, our conjecture is that information revelation occurs, and that the amount of revealed information will be higher with a leniency program. Unfortunately, testing whether an information revelation effect exists cannot be based on the true amount of information that would be hidden under the two regimes because there is an obvious problem of non-observability. However, we use the total amount of fines corresponding to a case as a proxy for the information revealed to the agency. Controlling for other factors determining the level of fines, a case which is well documented will lead to higher total penalties before the leniency scheme is applied. Consequently, we test the following hypothesis.

Hypothesis 1. The amount of fines per case prior to the application of the leniency scheme is larger than the amount of fines per case before introduction of the leniency programme.

Hypothesis 1 alone may not be sufficient for testing the information revelation effect. The authority may have implicitly changed its fining policy over time, showing up as spurious correlations with the introduction of the leniency program. However, given that there is sufficient variation of the degree of application of the program, an information revelation effect shall be observed also among the cases which legally fall under the leniency notice. Hence, an implication of the information revelation effect is that the evidence provided by the firms is reflected in the amount of leniency they receive. This leads to the following hypothesis. 
Hypothesis 2. After introducing the leniency programme, the amount of fines per case prior to the application of the leniency program will increase with the level of cooperation of the firms with the agency.

In order to test whether information provided by cartel members has a potential deterrence effect, we are interested in examining whether total fines per case have increased after applying the leniency program. Theoretical considerations are not decisive with regard to this question. Consequentially, we test the following competing hypotheses.

Hypothesis 3a. After introducing the leniency programme, the amount of fines per case after the application of the leniency program will be positively influenced by the level of cooperation of the firms with the agency.

Hypothesis 3b. After introducing the leniency programme, the amount of fines per case after the application of the leniency program will not be positively influenced by the level of cooperation of the firms with the agency.

How does information revelation under a leniency program reduce investigation and prosecution costs? Recall that firms may have a strong incentive to deliver evidence easy to collect, but perhaps a less strong incentive to deliver evidence hard to collect. While self-reporting from the first information category may not substantially decrease investigation costs, the latter one does. Here, the extent to which providing evidence costly to gather will imposes cost on the squealing firm in the form of higher fines or lost reputation as a credible cartelist decides on how much of a potential investigation cost reduction can be accomplished. Another point is 
how large the revealed information enables the agency to prove the anticompetitive conduct of co-conspirators. Hence, we expect that revealing information will to a certain extent facilitate the work of the agency to document the case and to present the evidence. However, prosecution costs may be increased since well documented cases expose more complex inter-relationships between cartelists, thus making the penalty assessment more intricate and expansive. Using the period of investigation as a proxy for investigation and prosecution cost which is plausible with constant input and technology, we arrive at the following competing hypothesis.

Hypothesis 4a. After introducing the leniency programme, the duration of the investigation and prosecution of a cartel case will decrease if firms cooperate within the framework of the leniency program.

Hypothesis 4b. After introducing the leniency programme, the duration of the investigation and prosecution of a cartel case will not decrease if firms cooperate within the framework of the leniency program.

\subsection{Deterrence}

Economic theory gives no conclusive answer on whether leniency programs provides firms with sufficient incentives to refrain from cartelizing an industry. There are factors which work in favor of deterrence after introducing the leniency program, while others work against it. First, a deterrence effect depends on which punishment strategies are applied (Ellis and Wilson 2001, Spagnolo 2003). Second, the reduced 
fines may make collusion less costly ex ante, but at the same time more risky in the sense of Harsanyi and Selten (1988).

Further note that to the extent that more information is revealed in face of a leniency program than without, deterrence may be amplified since the potential realizable fines increase and the agency's budget is sufficient to investigate more cases than before, i.e. the probability of investigating a case may rise. Further, the expected level of fines increases for late or non-reporting firms. Hence, it is an empirical question whether firms become more reluctant to join a collusive agreement after such a policy change.

For estimation purposes, it would be optimal to observe all the cartels established before and after the new policy was adopted. However, in reality we only observe those (illegal) cartels which could be detected by the agency or which disclosed itself to the public. In order to identify a deterrence effect, we may simply compare cartels which were established under similar circumstances but dissolved under different leniency regimes. Basically, we use the assumption that those cartels which are identified and investigated absent a leniency program are different from cartels which were investigated after the leniency scheme was introduced and in which cooperation played a central role. Dynamic models imply that, absent leniency schemes, there is a "marginal" cartel in which firms are indifferent between deviating and colluding because short-run gains from deviating and long-run gains from colluding are equal. When leniency programs have a deterrent impact, then the short-term gains from deviating (and reporting) are increased or the long-term benefits are decreased. 
Thus, deterrence implies a move of the marginal cartel into the set of unsustainable outcomes, while otherwise cartels which were not supportable as an equilibrium now become stable.

How can we then test whether a leniency program deters cartels? First, it is clear that in general the number of cartels detected before and after a certain regulatory event is a poor indicator of whether true propensity to collude has changed. This number may rise either because the new policy is efficient, or just because the total collusive activity has increased of which absolutely more but perhaps relatively less agreements were detected. However, this is only true in the long-run. In the short-run, we may observe a rise in the number of cartels detected which were established before it was known or could be expected that a leniency program would be introduced. Another interpretation is that firms expected a leniency program to be adopted when the cartel was established, but a sufficiently low discount rate was applied which made a cartel stable with regard to a deviation.

Thus, when we observe a short-run rise of leniency-based cartel detections, this may be interpreted as (weak) support for a destabilizing effect of this policy instrument. Within the framework of repeated games, cartels are deterred to a larger extent than without such a program. In contrast, when the number of cartels detected stays the same or falls after policy changes, a deterrence effect cannot be implied. Note that this way of testing the deterrence effect is only possible because we are able to distinguish between cartels established before and after the leniency program was introduced. Our considerations lead to the following competing hy- 
potheses:

Hypothesis 5a. The number of prosecuted cartels increases after introducing the leniency programme.

Hypothesis 5b. The number of prosecuted cartels does not increase after introducing the leniency programme.

Regarding the duration of cartels, we expect that if a deterrence effect of leniency programs is at work, shorter lived agreements are observed after the leniency policy change. If leniency programs have a deterrence effect, cartels which were established before the program was introduced should become fragile, and thus an earlier breakdown accompanied by self-reporting should occur. Otherwise, even some cartels that were not established under the old regime should be viable, thus prosecuted cartels tend to exhibit a longer life-span.

Hypothesis 6a. Cartels will be more stable after introducing the leniency programme.

Hypothesis 6b. Cartels will not be more stable after introducing the leniency programme.

Again, we may benefit from the fact that after the leniency policy was adopted, there is large variance associated with the level cooperation between firms and the European Commission. Under the assumption described above that only marginal cartels are affected by the leniency program while cartels detected through industry screening or other measures by the authority are not affected by leniency, we may 
compare the characteristics of these observations to conclude whether a deterrence effect exists.

Hypothesis 7a. Cartels which self-denounced their existence exhibit more instability than other cartels.

Hypothesis 7b. Cartels which self-denounced their existence do not exhibit more instability than other cartels.

\section{Data}

The data set consists of 53 cases falling under Art. 81 of the EC Treaty, or previously Art. 85, which were prosecuted and decided by the European Commission between 1990 and 2003, and whose decision was already published in August 2004. Only publicly available information was used for this study. With few exceptions the sample covers the complete set of cartels for which the 1996 EU Leniency Notice applied 17 For more recent antitrust abuses which are not covered by our sample, the modified 2002 Leniency Notice is relevant. The cases encompass in total 350 firms of which 245 firms were non-identical. We excluded trade associations from the sample as they usually just serve as a controlling and organizing institution of the cartel. The sample encompasses mostly horizontal agreements between competitors who attempted to collude on prices or quatities/market shares. However, in four of our cases the Commission objected the prevention of parallel trade by vertical cartels.

\footnotetext{
${ }^{7}$ Those remaining cases were not published yet at the time this study was conducted.
} 
[Table 1 about here.]

Not accounting for the time value of the money, the sample corresponds to a total sum of fines of $€ 6.714$ billion before and $€ 5.284$ billion after applying the leniency scheme. Table 1 reflects summary statistics for cartels falling under the Leniency Notice from 1996 and for those detected before. A first look reveals that the number of cases increased towards the end of the Nineties and after the Millennium, even accounting for the shorter time period covered before the leniency policy changed. Further, the total amount of fines before leniency increased sharply in the period covered by leniency. However, more than a third of this amount was reduced because firms cooperated with the Commission. Average duration of cartels was within a similar range as of cartels investigated in previous studies (Posner 1970, Evenett, Levenstein and Suslow 2001, Jacquemin, Nambu and Dewez 1981) $)^{8}$. However, cartels witnessed a one year shorter duration after establishing the leniency program. The shortest observed cartel endured only a quarter of a year, while the longest running cartel endured 23 years. Standard deviation is 4.16 for the pre-1996 sample and 5.94 for the post-1996 sample.

[Table 2 about here.]

\footnotetext{
${ }^{8}$ Not surprisingly, as the cartels studied in the literature vary between legal export cartels to illegal national or international price fixing conspiracies or market sharing agreements, there is variation in the duration variable. Some studies report significantly lower cartel life-span than ours such as Marquez (1994) and Dick (1996).
} 
Table 2 informs us about the distribution of the cartels across the industries. In line with previous findings (Asch and Seneca 1975), cartels detected come from markets of products which show few differentiation such as the chemical or the basic metal industry. Some of the cartels from markets with rather differentiated products are vertical agreements.

\section{Empirical results}

In this section we report our estimation results. Linear regression models are used to test Hypotheses 1-4 on the information revelation and cost reduction effects of the leniency program. Duration or hazard models are applied primarily to test Hypotheses 6 and 7 on the stability of cartel agreements contingent on whether a leniency program exists.

\subsection{Testing information revelation and investigation and pros- ecution cost reduction}

Next our models are presented which correspond to Hypotheses 1-4. 


$$
\begin{aligned}
& F_{i}=\alpha_{11}+\alpha_{12} L P_{i}+\alpha_{13} D C_{i}+\alpha_{14} N F_{i}+\alpha_{15} I N D_{i}+\epsilon_{i} \\
& F_{i}=\alpha_{21}+\alpha_{22} C O O P_{i}+\alpha_{23} D C_{i}+\alpha_{24} N F_{i}+\alpha_{25} I N D_{i}+\epsilon_{i} \\
& R F_{i}= \alpha_{31}+\alpha_{32} C O O P_{i}+\alpha_{33} D C_{i}+\alpha_{34} N F_{i}+\alpha_{35} I N D_{i}+\epsilon_{i} \\
& D I_{i}= \alpha_{41}+\alpha_{42} L P_{i}+\alpha_{43} D C_{i}+\alpha_{44} D C_{i}^{2}+\alpha_{45} N F_{i}+\alpha_{46} N C_{i}+ \\
& \alpha_{47} I N D_{i}+\epsilon_{i}
\end{aligned}
$$

$F_{i}$ is the amount of fines imposed by the European Commission in case $i$. Note that these are fines before application of the leniency program. $R F_{i}$ is the amount of fines after deducting leniency discounts. $L P$ is a dummy informing about whether the case was formally subject to the leniency program. $D C$ is the (legally validated) duration of the cartel. Legal and true duration are not necessarily identical. IND are industry dummies, $C O O P$ is a variable measuring the level of cooperation with the European Commission and $D I$ is the duration of the investigation. We call $\alpha$ the parameters to be estimated.

$D I$ refers to the duration between initiating the investigation, prosecution and reaching a decision since this should well proxy the cost of investigation. Further time elapsed for appeals to the Court of First Instance was not considered. We use two variants of the variable $C O O P$. The first one $(C O O P 1)$ is just the sum of the percentage leniency discount given by the Commission.9 The second one

\footnotetext{
${ }^{9}$ For example, if fines were reduced by $75 \%$ for one firm, by $40 \%$ for another firm, and not reduced for the remaining conspirators, COOP 1 would assume the value 115 .
} 
$(C O O P 2)$ is the ratio of the sum of the percentage leniency discount given and the sum of the percentage leniency discount potentially available according to the scheme. Both measures are no perfect proxies for cooperation because the degree of leniency potentially available is not observable. As a duration variable, we use average duration of the cartel. The period of cartel membership may differ between firms within a case. However, essentially the same results obtain if we use maximum duration instead.

Equation (1) corresponds to Hypothesis 1 which relates the introduction of the leniency program to an increase in the level of fines because of revelation effects. We include $D C$, the duration of the cartel, and $N F$, the number of firms, as variables likely determining the sum of fines at the case level. According to the fining scheme of the European Commission (1998), the marginal effect of duration is linearly related to the cartel fine. We control for industry specific effects.

Equation (2) is linked to Hypothesis 2. It differs to (1) in the leniency dummy which is replaced by a variable measuring the degree of cooperation with the agency. Note that equation (2) will be estimated for the restricted sub-sample of cartels for which the leniency notice applies. In order to measure a strong revelation effect such as articulated in Hypothesis (3), we just replace the dependent variable of (2) and do not change it apart from that. Finally, equation (4) is associated with Hypothesis (4) which relates the duration of the investigation to the presence of a leniency program. It is natural to control for the cartel duration, the number of firms and different countries involved, and for industry effects. A quadratic term for 
cartel duration is included to account for possible scale effects in the investigation and prosecution cost function.

We make the usual assumptions about the error terms such that OLS estimation delivers unbiased and efficient parameters. Table 3 shows the estimation results for (1) - (3). As regards the level of fines per case after the leniency program was introduced, we find support for Hypothesis 1. Controlling for other factors, the level of fines in cases which fall under the leniency scheme is about $€ 146$ million larger than in the remaining cases. However, this may just reflect that the fining policy changed over time. For example, some observers suspect that the Commissioners in charge may have an impact on enforcement. However, for a sample covering most of our observations, Schinkel, Carree and Günster (2004) find no support for this conjecture. Another possible reason for a temporal change of the level of fines one may think of is that larger, more serious infringements were detected after the leniency program was adopted. For the 29 cases for which we have information about the size of the relevant markets concerned, we unexpectedly find that under the leniency program, on average smaller cartels were detected.

Another implication of the information revelation effect is that in cases with a high degree of cooperation by cartel members with the Commission, higher fines should be observed before application of the leniency program (Hypothesis 2). Parameter estimates can be found in column 3 and 4 of Table 3. Again, our hypothesis is supported since both cooperation coefficients are positive and significantly different from zero. For the specification in which we use $C O O P 1$, we find that potential 
full cooperation would lead to an increase in the level of fines by $€ 214$ million. For the other specification which is based on $C O O P 2$, we find that a one percent increase in the leniency caused fine reduction would increase total fines by $€ 0.6$ million.

[Table 3 about here.]

Hypotheses 3a and 3b are developed in order to examine whether the information revelation effect is sufficiently strong such that the fines finally increase even after reduction based on leniency. Again, we only consider the post-1996 subsample. We test whether the level of cooperation has an impact on the total level of (after leniency) fines. We indeed find positive coefficients for the cooperation variables, although they are only significant at the $10 \%$ level in one specification. A further, perhaps weaker test would be to examine the level of fines before and after adopting the leniency program ${ }^{10}$ This regression (not reported) reveals a significant increase of fines payed by the firms after 1996 .

[Table 4 about here.]

Finally, we consider whether leniency programs help to reduce the investigation cost which we proxy by investigation duration (see Hypothesis 4). For this purpose, we estimate (4) whose results are reported in Table 4. By first looking at the fourth

\footnotetext{
${ }^{10}$ This test may be less powerful since temporal changes of the structure of the cartel and the fining policy cannot be excluded although we are not equipped with any evidence that these events occurred.
} 
column we observe that after 1996, the average duration of a cartel investigation decreased significantly by almost one and a half year. In order to exclude other potential effects on the antitrust enforcement such as better resource endowments of the European Commission in the late-Nineties, we restrict ourselves to the post1996 sample and check whether cooperation had an impact on the investigation duration (see columns two and three). We find that corresponding coefficients are negative but non-significant. This result may be due to above mentioned effect that investigation becomes cheaper but assessment of penalties becomes more expansive as cases become more complex.

\subsection{Testing cartel stability}

Hypothesis 5 is related to the question of whether cartel activity increases after adopting a leniency program. The total number of cartels and the number of cartels per year convicted rises considerably with the introduction of the leniency scheme (see Table 1). Starting from 2.5 cartels detected per year (and included in our study), the corresponding number jumps to 4.75 after introducing the program. However, as already discussed, this measure cannot provide convincing evidence about the success of this policy instrument since we do not observe a potential change in the cartel activity. Thus, we more closely consider testing the stability of cartels along Hypotheses 6 and 7.

Although it is natural to link stability of a cartel and its duration, using a duration variable begs the question of what the appropriate duration measure is. 
One may think of continuous periods in which cartels were able to raise prices above the competitive level. However, many scholars argue that even periods of price wars should be attributed to the cartel spell. Periods of price wars are necessary to stabilize a cartel when monitoring of rival's actions is imperfect (Green and Porter 1984, Slade 1989, Levenstein 1997). In our study we use the legally determined period in which cooperation took place through conspiratorial meetings and similar illegal measures.

Duration models are appropriate to be applied in the domain of cartel stability (Dick 1996), although others used OLS regression models based on different theoretic models (Jacquemin, Nambu and Dewez 1981, Marquez 1994) 11 Before selecting an appropriate model for the hazard rate, one may consult a pictorial representation of the empirical hazard rate (see Figure 1). In Figure 1, we draw the non-parametric Kaplan-Meier hazard rate estimator for two sub-samples. We distinguish between cartels before and after the leniency program adoption. Both curves are surprisingly similar. The maximum length of the cartels are similar and hazards are both monotonously increasing over duration with a seemingly similar slope. Hence, in our case a constant hazard model may imply inconsistent estimates. Rather a parametric version with flexibility regarding the (monotonous) change of the hazard rate

\footnotetext{
${ }^{11}$ Duration models were applied to study many economic problems such as firm survival (Cottrell and Nault 2004, Mata and Portugal 1994), plant survival (Chen 2002), duration of multinational subsidiaries (McCloughan and Stone 1998), technology adoption (Saloner and Shepard 1995), unemployment duration (Sider 1985), and the timing of a court settlement (Fournier and Zuehlke 1996). See Kiefer (1988) for a survey on economic duration data and hazard functions.
} 
over time seem to be appropriate for our estimation problem. This is provided by the Weibull model which allows for monotonously increasing or decreasing hazards:

$$
h(t)=\lambda p(\lambda t)^{(p-1)}
$$

where $p$ and $\lambda$ are model parameters and $t$ is time. Thus we use the following model to test Hypotheses $6 \mathrm{a}$ and $6 \mathrm{~b}$ :

$$
\ln \left(D C_{i}\right)=\beta_{11}+\beta_{12} L D_{i}+\beta_{13} N F_{i}+\beta_{14} N C_{i}+\beta_{15} I N D_{i}+\epsilon_{i}
$$

$\epsilon$ is an independent random variable such that $D C$ is Weibull distributed. $L D$ informs about the duration of the leniency programm during which the cartel persisted. Parameters to be estimated are denoted by $\beta$.

Besides the leniency dummy, variables having a likely impact on the stability of cartels are the number of firms, the number of different countries in which firms have their headquarters and industry dummies. Industry concentration and the market share of the cartel were identified as further determinants of cartel duration (Hay and Kelley 1974, Dick 1996). Moreover, the presence of large customers (Dick 1996), the homogeneity of the product (Jacquemin, Nambu and Dewez 1981, Dick 1996), business cycle effects (Dick 1996) and other demand (Marquez 1994) and organizational (Suslow 1991) variables were found to play a role in this context. However, to the extent that these variables are not covered by industry effects, we are not equipped with the relevant information to take them into account.

[Figure 1 about here.] 
The estimates for model (5) including all the observations are provided in the second column of Table 5. First observe that $L D$, the duration during which the cartel operated under the leniency policy, has a negative impact on the duration of the cartel but the coefficient is not significant. We cannot reject Hypothesis 6b. This finding may be due to the fact that either the leniency program is too weak to have an impact on cartel stability, or because the stabilizing and destabilizing forces of the leniency program are balanced. The results do not change qualitatively if we restrict ourselves to horizontal agreements, although the standard deviation of the $L D$-parameter decreases. The "number of firms"-coefficient enters the equation with a negative sign, indicating stability problems when the cartel gets too big. However, the positive sign of the parameter associated with the number of firms from different countries is positive suggesting multi-market effects on stabilizing a cartel. However, it should be remarked that both of these coefficients are statistically insignificant.

Using the whole data set may provide us with biased estimates since we pool cartels which were established before and after the leniency program came into force. The two sets of cartels may be fundamentally different. Let us illustrate this point. In the models of repeated games, there is a set of marginal cartel agreements in which firms are indifferent between entering and abstaining from a collusive agreement. If the leniency program is deterrent, cartels sufficiently close to the marginal cartel (in a certain sense) become unstable and thus would not be created under this policy. The new set of stable cartels is smaller, nevertheless may the new set of cartels show the same or perhaps different hazard rates. Hence, for a clear identification of 
the leniency program effect, we restrict our attention to cartels established before 1996. The corresponding results are displayed in Table 5, column three. However, there are no significant changes for the estimated parameters, making our conclusion stronger that the leniency program has no destabilizing effect.

In order to test Hypotheses $7 \mathrm{a}$ and $7 \mathrm{~b}$ we discriminate between cartels which were revealed by spontaneous self-reporting of cartel members and cartels which were detected by conventional means used by competition authorities such as industry screenings. Thus, we are interested in the self-denouncing effect of leniency programs. Again we use a Weibull model.

$$
\ln \left(D C_{i}\right)=\beta_{21}+\beta_{22} S R_{i}+\beta_{23} N F_{i}+\beta_{24} N C_{i}+\beta_{25} I N D_{i}+\epsilon_{i}
$$

$S R$ denotes a dummy for cases with spontaneous self-reporting. We use two different variations of this variable. $S R 1$ is a dummy for all cases in which spontaneous self-reporting occurred, while $S R 2$ is a dummy for cases in which self-reporting occurred and in which no investigation have been initiated in other jurisdictions. Table 5, column 3 shows the estimated parameters. Now we find that self-reporting occurs more often in longer-running (or more stable) cartels. This is not surprising if we take into account that the benefits from cheating and self-reporting may increase over time because the potential "load" of fines is temporally cumulated. However, another possible explanation of this fact is that these are not necessarily cartels which break down because of the destabilizing effect of the EU leniency program but because cartels were prosecuted in other jurisdictions. Antitrust enforcement 
across jurisdictions differs with the US having a more stringent regime which includes individual penalties for managers personally involved in criminal activities (Evenett, Levenstein and Suslow 2001).

Indeed, twenty of the cases in our European sample had counterparts in the US where investigations were initiated before. Further, in twenty of our (partially different) cases spontaneous self-reporting occurred. Only four of the latter were pure EU cases with no effect of investigations in other jurisdictions outside Europe. When we estimate (6) based on these "true" self-reporting cases, we obtain parameter estimates reported in Table 5, column 4. Here the coefficient for the incidence of self-reporting turns non-significant again.

\section{Conclusions}

The adoption of leniency or amnesty programs to fight organized crime recently became widespread in developed economies. The efficiency of such leniency programs is of high importance for the enforcement of law. In this paper, we empirically investigate the efficiency of the European Union Leniency Program from 1996 on corporate cartel activities. We compare characteristics of those cartels which were either detected or which self-reported during the period after leniency adoption with cartels detected without such a program in the six years before. We distinguish between short-run effects of the leniency program inducing firms to reveal information about criminal activities and thus to reduce the agency's investigation and prosecution 
costs and long-run effects of deterrence of collusive behavior.

Regarding the short-run effects, we find that information revelation occurs in the following sense. To the extent that the level of fines reflect evidence on the cartel activities available to the competition authority (controlling for other determinants of the level of fines), the authority obtains richer evidence after introducing the new policy, and information content increases with the level of cooperation between the cartel members and the agency. However, the effect of information revelation is not sufficiently strong in order to establish a positive link between cooperation between firms and the agency within the leniency program and fines finally payed by firms. Thus, information revelation has no deterrent impact on cartel activity.

Information revelation may be accompanied by a reduction of investigation and prosecution cost which we proxy by the duration of the investigation. Surprisingly, there is no statistically significant relationship between investigation duration and cooperation, although the average duration of an investigation decreased after adopting the leniency program. Perhaps, this is attributable to the fact that while investigation is facilitated by induced self-reporting, prosecution becomes more expansive as the assessment of penalties gets more time-consuming.

Finally, we consider the effect of the existence of a leniency program on the stability (or duration) of cartels. Although a sharp rise in the number of cartels convicted was observed after adopting the leniency program, this cannot be regarded as sufficient evidence of a deterrence effect of the program. The empirical results based on hazard models do not support the view that the leniency program 
destabilizes cartels as the hazard of stopping collusion does not significantly increase after adopting the new policy instrument. Even cartels which self-denounced its existence did not reveal a higher inherent risk to break up when taking into account that "opportunistic" self-reporting occurs if cartels are investigated in other jurisdictions already.

In order to reconcile the apparently conflicting results of the rise in the number of cartels convicted and the non-destabilizing effect of the program, we may resort to economical and political events accompanying the period of our analysis. In the beginning of the 1990s, barriers of trade and investment were lowered between national markets within the European Union. Evenett, Levenstein and Suslow (2001) argue that this gave rise to the establishment of new EU wide cartels. Since the average duration of a cartel is about six to seven years, the rise of convicted cartels may just coincide with the "natural" break-down of this wave of new cartels. The fact that those cartels do not exhibit a higher propensity to break-down than their pre-1996 counterparts supports this view.

In summary, our results confirm the view that the EU Leniency Program of 1996 is efficient as regards its short-term impact on cartels already under scrutiny. Possible cost reductions however seem to be modest in size. The belief of critics of the 1996 program (Motta and Polo 2003, Spagnolo 2003, Aubert, Kovacic and Rey 2004) who assert that the scheme is not powerful enough to deter anticompetitive behavior is supported by our empirical results. 


\section{References}

Abreu, D.: 1988, On the theory of infinitely repeated games with discounting, Econometrica 56, 383-396.

Apesteguia, J., Dufwenberg, M. and Selten, R.: 2004, Blowing the whistle, University of Bonn Working Paper.

Asch, P. and Seneca, J. J.: 1975, Characteristics of collusive firms, Journal of Industrial Economics 23, 223-237.

Aubert, C., Kovacic, W. and Rey, P.: 2004, The impact of leniency programs on cartels, Manuscript presented on the 2nd International industrial Organization Conference, Chicago .

Bar-Ilan, A. and Sacerdote, B.: 2004, The response of criminals and noncriminals to fines, Journal of Law and Economics 47, 1-17.

Chen, M.-Y.: 2002, Survival duration of plants: Evidence from the US petroleum refining industry, International Journal of Industrial Organization 20, 517-555.

Commission, E.: 1996, Commission notice on the non-imposition or reduction of fines in cartel cases, Official Journal C 207.

Commission, E.: 1998, Guidelines on the method of setting fines, Official Journal C 9.

Cottrell, T. and Nault, B. R.: 2004, Product variety and firm survival in the microcomputer software industry, Strategic Management Journal 25, 1005-1026. 
Dick, A. R.: 1996, When are cartels stable contracts?, Journal of Law and Economics 39, 241-283.

Evenett, S. J., Levenstein, M. C. and Suslow, V. Y.: 2001, International cartel enforcement: Lessons from the 1990s, World Economy 24, 1221-1245.

Fournier, G. M. and Zuehlke, T. W.: 1996, The timing of out-of-court settlements, RAND Journal of Economics 27, 310-321.

Green, E. J. and Porter, R. H.: 1984, Noncooperative collusion under imperfect price information, Econometrica 52, 87-100.

Harsanyi, J. and Selten, R.: 1988, A General Theory of Equilibrium Selection in Games, MIT Press, Cambridge MA.

Hay, G. A. and Kelley, D.: 1974, An empirical survey of price fixing conspiracies, Journal of Law and Economics 17, 13-38.

Innes, R.: 1999, Remediation and sel-reporting in optimal law enforcement, Journal of Public Economics 72, 379-393.

Jacquemin, A., Nambu, T. and Dewez, I.: 1981, A dynamic analysis of export cartels: The Japanese case, Economic Journal 91, 685-696.

Kaplow, L. and Shavell, S.: 1994, Optimal law enforcement with self-reporting of behavior, Journal of Political Economy 102, 583-606.

Kiefer, N. M.: 1988, Economic duration data and hazard functions, Journal of Economic Literature 26, 646-679. 
Levenstein, M.: 1997, Price wars and the stability of collusion: A study of the preworld war I bromine industry, Journal of Industrial Economics 45, 117-138.

Marquez, J.: 1994, Life expectancy of international cartels: An empirical analysis, Review of Industrial Organization 9, 331-341.

Mata, J. and Portugal, P.: 1994, Life duration of new firms, Journal of Industrial Economics 42, 227-245.

McCloughan, P. and Stone, I.: 1998, Life duration of foreign multinational subsidiaries: Evidence from UK northern manufacturing industry 1970-93, International Journal of Industrial Organization 16, 719-747.

Mocan, H. N. and Gittings, R. K.: 2003, Getting off death row: Commuted sentences and the deterrent effect of capital punishment, Journal of Law and Economics 46, 453-478.

Motta, M. and Polo, M.: 2003, Leniency programs and cartel prosecution, International Journal of Industrial Organization pp. 347-379.

Posner, R. A.: 1970, A statistical study of antitrust enforcement, Journal of Law and Economics 13, 365-419.

Saloner, G. and Shepard, A.: 1995, Adoption of technologies with network effects: An empirical examination of the adoption of automated teller machines, $R A N D$ Journal of Economics 26, 479-501. 
Schinkel, M. P., Carree, M. and Günster, A.: 2004, European antitrust policy: An empirical analysis of commission decisions and their appeal histories, 1964-2001, Paper presented at the EARIE 2004, Berlin .

Sider, H.: 1985, Unemployment duration and incidence: 1968-82, American Economic Review 75, 461-472.

Slade, M.: 1989, Price wars in price-setting supergames, Economica 56, 295-310.

Spagnolo, G.: 2003, Divide et impera: Optimal deterrence mechanisms against cartels (and organized crime), Mimeo .

Suslow, V.: 1991, Cartel contract duration: Empirical evidence from international cartels, Mimeo . 
Table 1. Descriptive statistics of international cartels fined by the European Commission between 1990 and 2003

\begin{tabular}{lrr}
\hline \hline Cartel decision & $1990-1995$ & $1996-2003$ \\
\hline Number of cases $^{*}$ Total fines (before leniency) $^{*}$ & 15 & 38 \\
Total reduction of fines $^{*}$ & $1.079,10$ & $5.438,61$ \\
Fines per case $^{*}$ & - & $1.953,14$ \\
Reduction of fines per case $^{*}$ & 71,94 & 143,12 \\
Average duration (years) & - & 51,40 \\
\hline \hline
\end{tabular}

${ }^{*}$ Numbers are expressed in million Edeflated on the basis of year 2000 using the OECD consumer price index for Europe.

Table 2. Distribution of cartels over industries

\begin{tabular}{|c|c|c|}
\hline Sectors & 1990-1995 & $1995-2003$ \\
\hline \multicolumn{3}{|l|}{ Manufacturing of } \\
\hline \multicolumn{3}{|l|}{ food products, beverages } \\
\hline and tobacco & - & 6 \\
\hline \multicolumn{3}{|l|}{ pulp, paper \& paper products; } \\
\hline publishing and printing & 1 & 1 \\
\hline \multicolumn{3}{|l|}{ chemicals, chemical products \& } \\
\hline man-made fibres & 3 & 16 \\
\hline \multicolumn{3}{|l|}{ other non-metallic mineral } \\
\hline products & 2 & 1 \\
\hline \multicolumn{3}{|l|}{ basic metals and fabricated } \\
\hline metal products & - & 5 \\
\hline machinery and equipment & 1 & 1 \\
\hline electrical and optical equipment & 1 & 1 \\
\hline Manufacturing n.e.c. & 2 & - \\
\hline Wholesale and retail trade & 1 & - \\
\hline Transport, storage and communication & 4 & 4 \\
\hline Financial intermediation & - & 2 \\
\hline \multicolumn{3}{|l|}{ Other community, social and } \\
\hline personal service activities & - & 1 \\
\hline Sum of observations & 15 & 38 \\
\hline
\end{tabular}


Table 3. OLS estimation results for equations (1), (2), and (3)

\begin{tabular}{|c|c|c|c|c|c|}
\hline Equation & $(1)$ & $(2)$ & $\left(2^{\prime}\right)$ & $(3)$ & $\left(3^{\prime}\right)$ \\
\hline & \multicolumn{5}{|c|}{ Dependent variables } \\
\hline & $F$ & $F$ & $F$ & $R F$ & $R F$ \\
\hline \multicolumn{6}{|l|}{ Variables } \\
\hline \multirow[t]{2}{*}{$L P$} & 146.53 & & & & \\
\hline & $(42.82)^{* * *}$ & & & & \\
\hline \multirow[t]{2}{*}{ COOP1 } & & 214.13 & & 100.60 & \\
\hline & & $(100.13)^{* *}$ & & $(55.74)^{*}$ & \\
\hline \multirow[t]{2}{*}{ СООР2 } & & & 0.60 & & 0.25 \\
\hline & & & $(0.32)^{*}$ & & $(0.176)$ \\
\hline \multirow[t]{2}{*}{$D C$} & 5.86 & 7.04 & 7.78 & -0.69 & -0.20 \\
\hline & $(3.50)$ & $(4.32)$ & $(4.33)$ & $(2.41)$ & $(2.42)$ \\
\hline \multirow[t]{2}{*}{$N F$} & 5.25 & 1.71 & -8.04 & -1.88 & -6.01 \\
\hline & $(3.00)^{*}$ & $(6.81)$ & $(8.24)$ & $(3.79)$ & $(4.62)$ \\
\hline$I N D$ & yes & yes & yes & yes & yes \\
\hline \multirow[t]{2}{*}{ CONSTANT } & -53.70 & -33.49 & 31.86 & 30.71 & 63.74 \\
\hline & $(57.31)$ & $(71.40)$ & $(55.69)$ & $(39.75)$ & $(31.18)^{*}$ \\
\hline$R^{2}$ & 0.464 & 0.671 & 0.660 & 0.795 & 0.785 \\
\hline Observations & 53 & 38 & 38 & 38 & 38 \\
\hline
\end{tabular}


Table 4. OLS estimation results for equation (4)

\begin{tabular}{|c|c|c|c|}
\hline \multirow[t]{3}{*}{ Equation } & $(4)$ & $\left(4^{\prime}\right)$ & $\left(4^{\prime \prime}\right)$ \\
\hline & \multicolumn{3}{|c|}{ Dependent variables } \\
\hline & $D I$ & $D I$ & $D I$ \\
\hline \multicolumn{4}{|l|}{ Variables } \\
\hline \multirow[t]{2}{*}{$L P$} & & & -1.45 \\
\hline & & & $(0.53)^{* * *}$ \\
\hline \multirow[t]{2}{*}{ COOP1 } & -0.001 & & 100.60 \\
\hline & $(0.005)$ & & $(55.74)^{*}$ \\
\hline \multirow[t]{2}{*}{ COOP2 } & & -0.33 & 0.25 \\
\hline & & (1.69) & $(0.176)$ \\
\hline \multirow[t]{2}{*}{$D C$} & 0.01 & 0.005 & 0.03 \\
\hline & $(0.23)$ & $(0.25)$ & $(0.18)$ \\
\hline \multirow[t]{2}{*}{$D C^{2}$} & -0.001 & -0.001 & -0.01 \\
\hline & $(0.01)$ & $(0.01)$ & $(0.01)$ \\
\hline \multirow[t]{2}{*}{$N F$} & 0.20 & 0.17 & -0.02 \\
\hline & $(0.15)$ & $(0.15)$ & $(0.07)$ \\
\hline \multirow[t]{2}{*}{$N C$} & 0.18 & 0.18 & 0.12 \\
\hline & $(0.71)$ & $(0.23)$ & $(0.17)$ \\
\hline$I N D$ & yes & yes & yes \\
\hline \multirow[t]{2}{*}{ CONSTANT } & 0.29 & 0.35 & 2.77 \\
\hline & $(1.23)$ & $(1.26)$ & $(1.05)^{* *}$ \\
\hline$R^{2}$ & 0.547 & 0.545 & 0.491 \\
\hline Observations & 38 & 38 & 53 \\
\hline
\end{tabular}


Table 5. Hazard rate estimation results for equations (4) and (5)

\begin{tabular}{|c|c|c|c|c|}
\hline \multirow[t]{3}{*}{ Equation } & $(5)$ & $\left(5^{\prime}\right)$ & $(6)$ & $\left(6^{\prime}\right)$ \\
\hline & \multicolumn{4}{|c|}{ Dependent variables } \\
\hline & $\ln (D C)$ & $\ln (D C)$ & $\ln (D C)$ & $\ln (D C)$ \\
\hline \multicolumn{5}{|l|}{ Variables } \\
\hline \multirow[t]{2}{*}{$L D$} & -0.09 & -0.06 & & \\
\hline & $(0.06)$ & $(0.07)$ & & \\
\hline \multirow[t]{2}{*}{$S R 1$} & & & 0.75 & \\
\hline & & & $(0.28)^{* * *}$ & \\
\hline \multirow[t]{2}{*}{$S R 2$} & & & & 0.418 \\
\hline & & & & $(0.59)$ \\
\hline \multirow[t]{2}{*}{$N F$} & -0.02 & -0.02 & 0.01 & -0.02 \\
\hline & $(0.06)$ & $(0.05)$ & $(0.09)$ & $(0.10)$ \\
\hline \multirow[t]{2}{*}{$N C$} & 0.08 & 0.08 & -0.09 & -0.07 \\
\hline & $(0.09)$ & $(0.09)$ & $(0.10)$ & $(0.12)$ \\
\hline$I N D$ & yes & yes & yes & yes \\
\hline \multirow[t]{2}{*}{ CONSTANT } & 2.15 & 2.12 & 1.78 & 2.47 \\
\hline & $(0.33)^{* * *}$ & $(0.32)^{* * *}$ & $(0.36)^{* * *}$ & $0.37^{* * *}$ \\
\hline$\lambda$ & 0.149 & 0.138 & 0.165 & 0.162 \\
\hline$P$ & 1.497 & 1.583 & 2.041 & 1.836 \\
\hline Log-likelihood & -141.204 & -130.266 & -32.534 & -35.642 \\
\hline Observations & 53 & 48 & 38 & 38 \\
\hline
\end{tabular}




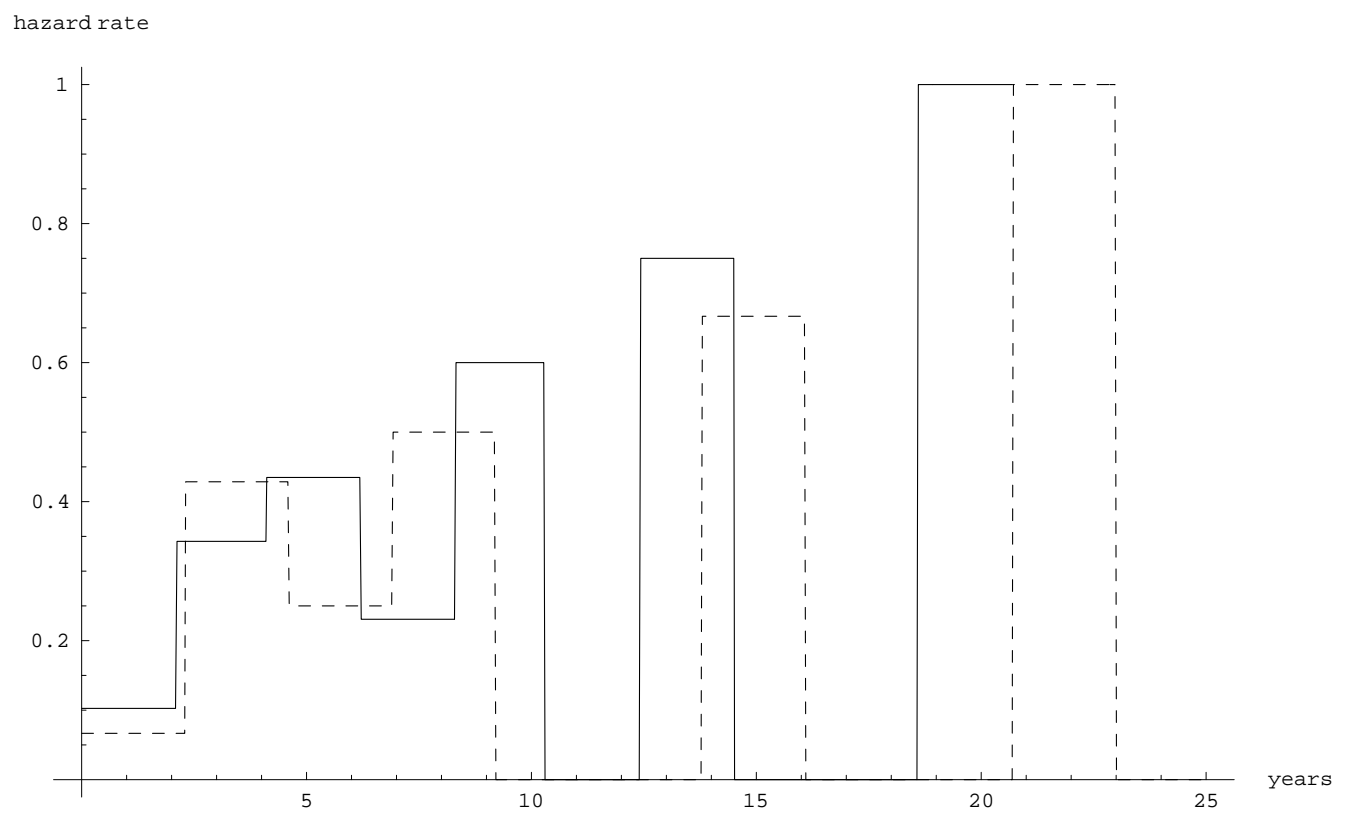

Figure 1. Empirical hazard function, straight (dashed) line corresponds to cartels detected (not) under the EU leniency program 